\title{
A soberania alimentar que desperta e aprofunda os saberes em direitos por terra, por comida de verdade e por igualdade de gênero
}

Food sovereignty that awakens and deepens the knowledge of the rights for the land, authentic food and gender equality

Soberanía alimentaria que despierta y profundiza el conocimiento sobre los derechos a la tierra, la comida real y la igualdad de género

\author{
Érika Maria Marcondes Tassi ${ }^{1}$
}

Islandia Bezerra $^{2}$

RESUMO: Soberania Alimentar é compreendida como sendo o direito dos povos de definir suas próprias políticas voltadas aos sistemas alimentares (produção, distribuição, comercialização, acesso, consumo e aproveitamento biológico), bem como protegê-lo e regulamentá-lo sob a ótica da sustentabilidade. Nesse sentido, a produção de alimentos agroecológicos em sinergia com a natureza possibilita o resgate de práticas sobre o que produzir e o que comer. O cenário que se desenhou foi o resgate de práticas de produçãoconsumo das Plantas Aimentícias Não Convencionais (PANC) como ponto central de problematização. Neste relato de experiência, refletimos sobre soberania alimentar a partir de distintas dimensões. Assim, temas como a participação das mulheres no cotidiano alimentar, as PANC como impulsionadoras da sociobiodiversidade e o resgate da alimentação tradicional e saudável inspiraram o debate. Para tanto, foi realizado um breve levantamento teórico sobre os temas e, na sequência, foi realizada uma Roda de Conversa. Evidenciou-se, portanto, que os temas abordados despertaram um grande interesse por parte do público participante, sobretudo pela possibilidade de concretizar a soberania alimentar no cotidiano das suas famílias, reconhecendo, ao mesmo tempo, a necessidade de transformar as relações sociais, em relação às mulheres, por exemplo, e também com a natureza, fomentando, assim, a agroecologia.

Palavras-chave: Soberania. Segurança Alimentar e Nutricional. PANC. Agroecologia.

ABSTRACT: Food Sovereignty is understood as the right of peoples to define their policies related to food systems (production, distribution, marketing, access, consumption, and biological exploitation), as well as to protect and regulate it from the perspective of sustainability. In this sense, the production of agroecological foods in synergy with nature enables the rescue of practices on what to produce and what to eat. The scenario that was designed was the rescue of production-consumption practices of Unconventional Food Plants

\footnotetext{
${ }^{1}$ Doutora em Ciência da Nutrição pela Universidade Estadual de Campinas, São Paulo, Brasil; professora associada da Faculdade de Medicina da Universidade Federal de Uberlândia, Minas Gerais, Brasil; membro do Núcleo de Estudos em Agroecologia e Produção Orgânica (NEA) no Centro de Incubação de Empreendimentos Populares Solidários (Cieps/PROEXC/UFU) (erikatassi@ufu.br).

2 Doutora em Ciências Sociais pela Universidade Federal do Rio Grande do Norte, Brasil, com estágio pósdoutoral em Ciências e Desenvolvimento Regional na Universidade Autónoma de Chapingo, México; professora associada do Departamento de Nutrição da Universidade Federal do Paraná, Brasil; educadora voluntária na Escola Latino Americana de Agroecologia (ELAA); coordenadora do Grupo de Pesquisa moNGARU (alimentar): Agreocologia, Soberania Alimentar e Cultura no Paraná; membro do Fórum Estadual de Soberania e Segurança Alimentar e Nutricional do Paraná (FESSAN/PR); da Rede Brasileira de Pesquisa em Soberania e Segurança Alimentar e Nutricional (RPSSAN) e do Grupo de Trabalho Agroecología Política CLACSO; presidenta da Associação Brasileira de Agroecologia (ABA) (islandia@ufpr.br).
} 
(UFP) as a central point of problematization. In this experience report, we reflect on food sovereignty in different dimensions. Thus, topics such as women's participation in daily food, UFP as drivers of socio-biodiversity and the rescue of traditional and healthy food inspired the debate. To this end, a brief theoretical survey on the themes was carried out and a conversation circle was held. It was evident, therefore, that the topics addressed aroused great interest from the participants, especially for the possibility of achieving food sovereignty in the daily lives of their families and at the same time recognizing the need to transform social relations - for example in relation to women - and also with nature, thus promoting agroecology.

Keywords: Food sovereignty. Food and nutrition security. UFP. Agroecology.

RESUMEN: La soberanía alimentaria se entiende como el derecho de los pueblos a definir sus propias políticas dirigidas a los sistemas alimentarios (producción, distribución, comercialización, acceso, consumo y uso biológico), así como a protegerlo y regularlo desde la perspectiva de sostenibilidad. En este sentido, la producción de alimentos agroecológicos en sinergia con la naturaleza permite rescatar prácticas sobre qué producir y qué comer. El escenario que se diseñó fue el rescate de las prácticas de producción y consumo de las Plantas Alimentarias No Convencionales (PANC) como punto central de la problematización. En este informe se refleja la experiencia de la soberanía alimentaria en diferentes dimensiones. En este sentido, temas como la participación de las mujeres en la alimentación diaria, las PANC como impulsores de la socio-biodiversidad y el rescate de la alimentación tradicional y saludable inspiraron la discusión. Con este fin, se realizó una breve encuesta teórica sobre los temas y se realizó una rueda de conversación. Los temas abordados despertaron un gran interés por parte del público que participó, sobre todo debido a la posibilidad de lograr la soberanía alimentaria en la vida cotidiana de sus familias y al mismo tiempo reconocer la necesidad de transformar las relaciones sociales, por ejemplo, en relación con las mujeres, y también con la naturaleza, promoviendo de esta forma la agroecología.

Palabras clave: Soberanía. Seguridad alimentaria y nutricional. PANC. Agroecología.

\section{INTRODUÇÃO}

Implementar uma política pública que materialize a Reforma Agrária em um país com grandes desigualdades sociais como o Brasil segue sendo uma demanda atual e imprescindível. Não apenas porque essa ação poderia democratizar o acesso aos meios de produção - como a terra -, mas também porque garante aos povos as condições necessárias para sua reprodução social e cultura e, assim, materializar a Soberania e Segurança Alimentar e Nutricional (SSAN). Entretanto, um dos maiores desafios em uma política de Reforma Agrária, para além do acesso à terra, é a política também incorporar em seus princípios, a promoção das condições (acesso ao crédito e à assessoria técnica, por exemplo) para que as famílias agricultoras sigam com seus processos produtivos, sem necessariamente, reproduzir as práticas destrutivas que exploram pessoas e natureza, tal como o sistema agroexportador. 
Sobre essa assertiva, trazer o debate da Soberania Alimentar e da Agreocologia torna-se imperativo. Para a Via Campesina Internacional (VCI), Soberania Alimentar é uma definição que foi referendada no Fórum Mundial de Soberania Alimentar, em 2001, e a sua proposta nasceu como uma estratégia de enfrentamento às políticas neoliberais, nas quais predomina $\mathrm{o}$ poder decisório das grandes corporações do sistema agroalimentar mundial. Na íntegra, a Via define Soberania Alimentar como sendo o direito dos povos de definir suas próprias políticas agropecuárias e de alimentação, bem como proteger e regulamentar a produção agropecuária e o mercado nacional, objetivando alcançar o desenvolvimento sustentável. Ela não nega o comércio internacional, porém defende a opção de formular políticas e fomentar práticas comerciais que sirvam aos direitos das populações disponibilizando métodos e produtos alimentícios inócuos, nutritivos e ecologicamente sustentáveis.

Essa concepção, portanto, viabiliza dialogar com a Agroecologia já que na sua condição de ciência, movimento e prática nos oportuniza a praticar, produzir, colher e consumir alimentos em sinergia com a natureza e nos possibilita resgatar práticas sobre o que produzir e o que comer. Nesse contexto, é que a produção-processamento-consumo de Plantas Alimentícias Não Convencionais (PANC) pode contribuir para concretizar ações estratégicas no debate sobre a sustentabilidade da agricultura familiar e, por conseguinte, sobre a própria Reforma Agrária como sendo necessária e fundamental para garantir a soberania alimentar.

Ao compreender essa construção conceitual de soberania alimentar, que, por sua vez, se alinha à Agroecologia, e que, por conseguinte reverbera na SSAN, trazemos outras dimensões, por exemplo, uma análise sob uma perspectiva feminista, considerando assim, uma realidade objetiva que impõe às mulheres uma responsabilidade quase que exclusiva sobre o ato de alimentar. Para tanto, trazemos as análises das autoras Giordani, Bezerra e Anjos (2017, p. 434) sobre um elemento analítico e utilitário do "bem viver" que permite referenciar o ato cotidiano de alimentar (a si mesmo e aos demais) como um ato político. Para as autoras "a produção do alimento agroecológico aciona diferentes redes de sentido, como a integração e a dependência com o espaço; e o conceito ampliado de saúde, que envolve um bem-estar que se completa na tomada de consciência em relação à necessidade de integração sociedade-natureza. São discussões em que o alimento é referido como comida de verdade, potencialmente produtiva de significados que extrapolam a função biológica e nutricional. É nessa perspectiva que são trazidos o conceito do bem viver e seus desdobramentos imediatos, como o bem e bom comer. 
Alinhadas a esta assertiva, é possível inferir que as mulheres assumem o protagonismo do ser/fazer da relação agroecologia, alimentação e nutrição uma realidade possível. Sobre essa constatação, Esteve (2017) demonstra o papel fundamental das mulheres em materializar tais ações. Segundo a autora, entre $60 \%$ e $80 \%$ da produção de alimentos nos países do hemisfério Sul é realizada por mulheres. No entanto, esses processos não são contabilizados na macroeconomia, por tal motivo, são invisibilizados.

Diante dessas breves constatações, urge pensarmos como seria possível, por exemplo, viabilizar processos pedagógicos que, por sua vez, resultem em transformações sociais necessárias. Assim, menciona-se a importância da criação e implementação de políticas, programas e ações públicas que sejam capazes de impulsionar o rompimento de paradigmas e assim viabilizar, na prática, uma compreensão ampliada sobre Soberania Alimentar, Agroecologia, alimentação e nutrição e, por fim, o reconhecimento do papel das mulheres. Cita-se, como exemplo, a Política Nacional de Agroecologia e Produção Orgânica (PNAPO), que traz em uma das suas sete diretrizes a intenção de contribuir para redução das desigualdades de gênero, por meio de ações e programas que promovam a autonomia econômica das mulheres (BRASIL, 2012).

Essa referência às mulheres na PNAPO é mais um indicativo da influência da Agroecologia na construção de um projeto de sociedade mais justo e equitativo que traz, em seu cerne, as complexas dimensões do ser/estar. A partir dessas constatações, podemos inferir que a presença das mulheres - em vários países do mundo - e, sobretudo, permeando as várias dimensões dos sistemas alimentares - preparar a terra, plantar, colher, desenvolver produtos, comercializar, distribuir, prover o acesso e o consumo - possui significativa relevância nas ações cotidianas da Soberania Alimentar dos povos. Contudo, também é necessário repensar as práticas das tarefas domésticas que, historicamente, impuseram às mulheres a exclusividade do cuidar, do alimentar, do limpar. Por que, na família, o homem é responsável por produzir para comercializar e a mulher é responsável por produzir para alimentar? E por que essa produção da mulher não possui a mesma importância que a do homem? São questões.

Voltando ao tema da alimentação, o Brasil é um país com uma "megadiversidade" biológica, apresentando aproximadamente $22 \%$ da diversidade vegetal existente no mundo (MEGADIVERSIDADE, 2009), entretanto estudos mostram que são perdidos por ano entre uma a duas toneladas por hectare de recursos vegetais que poderiam ser empregados para 
alimentação (RAPOPORT; MARGUTTI; SANZ, 1997; DÍAZ-BETANCOURT et al., 1999; FAO, 2009).

No entanto, a alimentação da humanidade vem, ao longo dos anos, tornando-se cada vez mais limitada a algumas espécies, como trigo, batata, milho e arroz, ${ }^{2}$ sendo que o sistema agroalimentar atual - voltado para o monocultivo de commodities como, por exemplo, soja, milho e cana-de-açúcar - vem minimizando as variedades no cotidiano alimentar, tanto na produção como no consumo. Alia-se a essa reflexão o não interesse na produção de alimentos que não tenham "valor de mercado" (LADIO, 2005). Convém mencionar, ainda, que o sistema alimentar atual - que tem nas suas bases o modelo dos grandes latifúndios - também ocasiona outros males à saúde (das pessoas e do ambiente), devido à necessidade de produção em grande escala, por exemplo, essas commodities são cultivadas de forma intensiva e com uso excessivo de agrotóxicos (RAPOPORT; SANZ; LADIO, 2001), os quais, segundo Ferment, Zanoni e Nodari (2010), penetram e bioacumulam nos tecidos, apresentando consequências variáveis para o organismo humano, sendo associado com o aumento da propensão carcinogênica e outros tipos de doenças (STOPPELLI, 2005).

Assim, as diversas espécies ainda subexploradas da flora brasileira, que em alguma época fizeram parte do cotidiano alimentar de muitas famílias, por não terem um significativo "valor comercial" foram sendo esquecidas. Nesses termos, Miranda (2009) afirma que tais espécies podem constituir uma fonte de renda alternativa e uma opção de diversificação cultural, na atividade agropecuária, principalmente na agricultura familiar. Além disso, essas plantas não convencionais são uma alternativa para o aproveitamento da biodiversidade brasileira, apresentando boas fontes nutricionais e baixo custo (QUEIROZ et al., 2015). É a partir dessa constatação que trabalhamos as PANC.

O termo PANC foi criado em 2007 pelo biólogo e professor Valdely Ferreira Kinupp e referese a todas as plantas que não estão incluídas em nosso cardápio cotidiano, que geralmente são consideradas como "mato" ou "daninhas". As PANC apresentam uma ou mais partes comestíveis, sendo elas espontâneas ou cultivadas, nativas ou exóticas (KINUPP, 2007; KUNKEL, 1984).

As plantas alimentícias apresentam teores significativos de sais minerais, vitaminas, fibras, amido, carboidratos e proteínas. Além disso, algumas espécies possuem teores de nitrogênio, fósforo e potássio superiores às plantas leguminosas utilizadas tradicionalmente como 
adubações verdes (QASEN, 1992; PARYLAK, 1994). Algumas são utilizadas para produzir medicamentos, óleos essenciais, extratos e chás, e várias espécies apresentam características apícolas, podendo fornecer néctar e pólen aos polinizadores (BRANDÃO et al., 1985).

Essas plantas apresentam características como rápido desenvolvimento, alta plasticidade fenotípica, produção de sementes em grandes quantidades e com alta viabilidade, associadas com eficientes mecanismos de dispersão e dormência, e reprodução por autogamia, favorecendo o estabelecimento dessas espécies em locais continuamente alterados. Dessa forma, as PANC adaptam-se bem ao ambiente, dispersando-se em meio a lavouras, hortas abandonadas, quintais e calçadas, sendo resistentes e desenvolvendo-se mesmo em condições adversas para a maior parte das plantas (BAKER, 1965; BAKER, 1974).

Outra vantagem das PANC é que, por muitas delas serem nativas do respectivo bioma, elas já são naturalmente adaptadas, sendo, portanto, desnecessário o uso agrotóxico para seu cultivo, o que proporciona maior segurança alimentar e nutricional para a população e menores riscos para o meio ambiente (BRASIL, 2010). Assim, o cultivo dessas plantas pode se tornar fonte de renda para a população em geral, principalmente para agricultores familiares, em comunidades de baixa renda e nas periferias dos grandes centros urbanos.

Considerando a relevância das PANC, foi elaborada uma proposta para roda de conversa na V Jornada Universitária em Defesa da Reforma Agrária (JURA), promovida pela Universidade Federal de Uberlândia (UFU). Os temas abordados foram: composição nutricional, receitas e informações gerais de algumas PANC (Hibisco, Maxixe, Ora-pro-nóbis, Taioba, Jurubeba, Cambuquira, Beldroega e Moringa), sem perder de vista outras dimensões complexas do sistema alimentar, tais como a questão de gênero e a Reforma Agrária. A partir dessa breve contextualização, o objetivo desse relato de experiência foi refletir sobre soberania alimentar, agroecologia, participação das mulheres no cotidiano alimentar e também conhecer e explorar as PANC visando o aproveitamento da biodiversidade e o resgate da alimentação tradicional e saudável. 


\section{METODOLOGIA}

Esse estudo possuiu abordagem qualitativa, baseado em conhecimentos teóricos através de levantamentos bibliográficos, de trabalhos acadêmicos (artigos, monografias, teses, dentre outros) referentes aos temas, bem como de conhecimentos práticos.

O texto foi apresentado para reflexão da V Jornada Universitária em defesa da Reforma Agrária (JURA), realizada na Universidade Federal de Uberlândia (UFU), em maio de 2019, submetido a debate em Roda de Conversa. Em princípio, com 15 participantes, entre agricultores e agricultoras da agricultura familiar, estudantes da graduação e da pós-graduação de distintas áreas do conhecimento e pessoas afetas ao tema. Ao término da atividade contávamos com 22 pessoas.

A Roda tomou como princípio metodológico o Diálogo de Saberes (DS), que, segundo Rezende (2018), inspira-se na experiência histórica das comunidades. Tardin (2006), por sua vez, cita que o DS, nada mais é que a constante busca por compreender o sistema do planejarfazer-ser os agroecossistemas familiares ou coletivos que pautam a Agroecologia como sendo estratégico para a autonomia dos povos no produzir-consumir alimentos agroecológicos.

\section{RESULTADOS E DISCUSSÃO}

A Feirinha Solidária da UFU é um projeto desenvolvido pelo Centro de Incubação de Empreendimentos Populares Solidários (Cieps), incubadora da Universidade Federal de Uberlândia (UFU). O projeto teve como objetivo unir os trabalhadores e trabalhadoras do campo e da cidade em torno da produção e do consumo de alimentos agroecológicos, promovendo um espaço de convivência e práticas alimentares saudáveis entre a comunidade acadêmica e sociedade civil. Foi nesse cenário que realizamos a roda.

\section{Roda de Conversa: de forma circular, dialogamos}

Inicialmente, foi estabelecido como seria a estrutura da Roda de Conversa na JURA. Para começar foi feita uma apresentação sobre a definição de Segurança Alimentar e Nutricional, utilizando exemplos práticos para facilitar a compreensão das pessoas participantes. Percebeuse, a partir da fala, que tanto a produção quanto o consumo de alimentos agroecológicos vem sendo foco de discussão em vários âmbitos e que, para o agricultor e para a agricultora 
familiar, é uma forma de valorizar do trabalho da mulher "Para a soberania alimentar é importante a participação da mulher, ela também cuida dos alimentos agroecológicos no campo" (Participante, 2019).

Foram apresentadas as PANC: Caxi, Ora-pro-nóbis, Caruru, Hibisco, Beldroega, Taioba, Almeirão Roxo, Peixinho, Serralha, Bertalha e Azedinha. Foi observado amplo interesse nas receitas das preparações culinárias por parte dos participantes. Em seguida, falou-se sobre outras PANC que eles conhecem, como o pepino selvagem e a baunilha do cerrado. No entanto, o que se constata é que o cultivo e o consumo das PANC têm diminuído em todas as regiões (rurais e urbanas) do país e também entre as classes sociais. Debater sobre o que temos em termos de conhecimento sobre as PANC é uma forma de abordar distintas dimensões do atual sistema alimentar: o acesso à terra (aqui se debateu sobre reforma agrária), alinhando ao debate do papel da mulher nas práticas cotidianas como sendo a única responsável por alimentar a família, mas que, ao mesmo tempo, não tem direito sobre a terra. Conectando ainda às práticas alimentares, referenciando as PANC como uma forma de promoção aos hábitos alimentares saudáveis e culturalmente referenciados. Foi mencionado também que produzir e consumir PANC alinhado à agroecologia significa resistir ao modelo de produção de alimentos que destrói a saúde das pessoas e do ambiente: "produzir alimentos agroecológicos é importante, pois há um cuidado na forma da produção e da pessoa que vai consumir" (Participante, 2019).

Algumas preparações culinárias com PANC são elaboradas por estudantes do curso de nutrição e são comercializadas no projeto da Feirinha Solidária. Essa ação visa fomentar o consumo a partir de preparações variadas, estimulando habilidades culinárias em todas as pessoas da família - desconstruindo, assim, o papel da mulher como a única responsável por preparar a refeição - e problematizando o aumento do consumo de produtos ultraprocessados, cujo apelo à praticidade leva centenas de milhares de pessoas a aderir a tais práticas.

\section{CONSIDERAÇÕES FINAIS}

Observou-se na roda de conversa que há um grande interesse pelas PANC e que o conhecimento sobre elas pode levar ao consumo. Em que pesem as limitações do tempo que durou a roda de conversa, bem como as limitações de tratar em poucas linhas sobre temas tão complexos, foi gratificante perceber que temas como soberania alimentar, Agroecologia, 
PANC, resgate da alimentação tradicional e saudável e, em alguma medida, questões de gênero se fizeram presentes no debate de uma forma problematizadora. De acordo com Marin (2009), a interligação de saberes acumulados pela ciência e pelos saberes populares sobre os agroecossistemas é o ponto de partida para a construção de condições objetivas e subjetivas para apoiar o processo de transformação - entre as pessoas e para com a natureza - das formas de produzir e consumir.

Os saberes dos que praticam a Agroecologia, seja na produção, seja no consumo, no seu cotidiano técnico e/ou prático, mas também os saberes de quem a desconhece como ciênciamovimento-prática - mas, que se dispõe a conhecer, experimentar e praticar, dispararam debates, reflexões e, espera-se: transformações. Reconhecer que a extensão universitária potencializa essa troca de saberes é fundamental para seguirmos transformando.

\section{REFERÊNCIAS}

BAKER H. G. Charcteristics and modes of origin of weeds. In: Baker H. G., STEBBINS, G. L. (ed.). The genetics of colonizing species. New York: Academic Press; 1965. p. 147-172. Doi: 10.1146/annurev.es.05.110174.000245.

BAKER H. G. The evolution of weeds. Annual Review of Ecology and Systematics, v. 5, p. 1-24, 1974.

BRASIL. Decreto $\mathrm{n}^{\circ}$ 7.794, de 20 de agosto de 2012. Institui a Política Nacional de Agroecologia e Produção Orgânica. Diário Oficial da União, Brasília, DF, 20 ago. 2012.

BRASIL. Ministério da Agricultura, Pecuária e Abastecimento. Secretaria de Desenvolvimento Agropecuário e Cooperativismo. Manual de hortaliças não convencionais. Brasília: MAPA; 2010.

BRANDÃO M. et al. Novos enfoques para plantas consideradas daninhas. Informe Agropecuário, Belo Horizonte, v. 11, n. 129, p. 3-12, 1985.

DÍAZ-BETANCOURT, M. et al. Weeds as a source for human consumption: a comparison between tropical and temperate Latin America. Revista Biológica Tropical, San Jose, v. 46, n. 3, p. 329-338, set. 1999.

ESTEVE, E. V. O negócio da comida: quem controla nossa alimentação? São Paulo: Expressão Popular, 2017.

FAO. El estado mundial de la agricultura y la alimentación. Roma: FAO, 2009. Disponível em: http://www.fao.org/3/i0680s/i0680s.pdf. Acesso em: 15 jan. 2020.

FERMENT, G.; ZANONI, M.; NODARI, R. O. Estudo de caso: sojas convencionais e transgénicas no planalto de Rio Grande do Sul. Brasil: Ministério do Desenvolvimento Agrário, 2010. 
GIORDANI, R.; BEZERRA, I.; ANJOS, M. Semeando agroecologia e colhendo nutrição: rumo ao bem e bom comer. In: IPEA. A política nacional de agroecologia e produção orgânica no Brasil: uma trajetória de luta pelo desenvolvimento rural sustentável. Brasília: IPEA, 2017. p. 433-454.

KINUPP, V. F. Plantas alimentícias não convencionais da Região Metropolitana de Porto Alegre, RS. 2007. 590 f. Tese (Doutorado em Fitotecnia) - Faculdade de Agronomia, Universidade Federal do Rio Grande do Sul, 2007.

KUNKEL, G. Plants for human consumption: an annotated checklist of the edible phanerogams and ferns. Koenigstein: Koeltz Scientific Books, 1984.

LADIO, A. Malezas exóticas comestibles y medicinales utilizadas em poblaciones del noroeste patagônico: aspectos etnobotánicos y ecológicos. Boletín Latinoamericano y del Caribe de Plantas Medicinales y Aromáticas, v. 4, n. 4, p. 75-80, julio 2005.

MARIN. J. O. B. Agricultores familiares e os desafios da transição agroecológica. Revista UFG, Goiânia, Ano XI, n. 7, p. 38-45, dez. 2009.

MEGADIVERSIDADE.

Disponível

em:

http://www.conservation.org/global/brasil/publicacoes/Documents/Megadiversidade_desafios _cientificos.pdf. Acesso em: 20 jan. 2020.

MIRANDA, M. R. M. et al. O potencial da Ora-pro-nóbis na diversificação da produção agrícola. Revista Brasileira de Agroecologia, Curitiba, v. 4, n. 2, p. 3.350-3.354, 2009.

PARYLAK, D. Uptake of nutrients by weeds and winter triticale at different development stages. Rolniczej W. Szczecinie Rolnictwo, v. 58, p. 185-188, 1994.

QASEN, J. R. Nutrient accumulation by weeds and their associated vegetable crops. Journal of Horticultural Science and Biotechnology, v. 67, p. 189-195, 1992. Doi: 10.1080/00221589.1992.11516236.

QUEIROZ, C. R. A. A. et al. Ora-pro-nóbis em uso alimentar humano: percepção sensorial. Revista Verde, Pombal, v. 10, n. 3, p. 1-5, 2015. Doi: 10.18378/rvads.v10i3.3393.

RAPOPORT, E. H.; MARGUTTI, L. S.; SANZ, E. H. Plantas silvestres comestibles de la Patagonia Andina: Exóticas. v. I. Bariloche. Ediciones de Imaginaria, 1997.

RAPOPORT E. H.; SANZ, E. H.; LADIO, A. H. Plantas Silvestres comestibles de la Patagonia Argentino-Chilena: Exóticas. v. II. Bariloche. Ediciones de Imaginaria, 2001.

REZENDE, S. A. Diálogo de saberes no encontro de culturas: o desafio da construção do conhecimento em agroecologia na educação do campo. 2018. Dissertação (Mestrado em Educação) - Faculdade de Educação, Universidade Federal do Paraná, Curitiba, 2018.

STOPPELLI, I. M. B. S.; MAGALHAES C. P. Saúde e segurança alimentar: a questão dos agrotóxicos. Ciência \& Saúde Coletiva, Rio de Janeiro, v. 10, suppl. 0, set./dez. 2005. Doi: 10.1590/S1413-81232005000500012.

TARDIN, J. M. Diálogo de saberes no encontro de culturas: sistematização. Lapa, 2006 [mimeo]. 
VIA CAMPESINA INTERNACIONAL. Declaración final del Foro Mundial Sobre Soberanía Alimentaria. $2001 . \quad$ Disponível em:

http://www.movimientos.org/cloc/show_text.php3?key=1178. Acesso em: 20 jan. 2020. 